\title{
Sobre o que Ressoa e Faz Eco: Voz, Música e Lalíngua no Tratamento do
}

\author{
Autismo \\ Beatriz Alves Viana* \\ Universidade Federal do Rio de Janeiro - UFRJ, Rio de Janeiro, RJ, Brasil \\ ORCID: https://orcid.org/0000-0002-8758-8913 \\ Kemylle Mesquita Brito** \\ Universidade Federal do Ceará - UFC, Sobral, CE, Brasil \\ ORCID: https://orcid.org/0000-0003-2116-4453 \\ Luis Achilles Rodrigues Furtado*** \\ Universidade Federal do Ceará - UFC, Sobral, CE, Brasil \\ ORCID: https://orcid.org/0000-0003-1606-2073
}

\section{RESUMO}

Esse artigo aborda a articulação entre os conceitos psicanalíticos de lalíngua e de voz, pensados a partir da clínica com sujeitos autistas. Com base nas vinhetas clínicas retiradas da literatura e da experiência de trabalho em serviços de Saúde Mental, busca-se investigar de que formas essas noções teóricas se apresentam primordialmente no ato de escuta e como estas podem indicar uma direção de tratamento no autismo a partir da música. A musicalidade da voz materna, por meio de uma ressonância que não se prende ao sentido, transmite uma invocação ao infans para que este advenha como sujeito, produzindo marcas a serem lidas. É necessário que tal invocação, para que possa ressoar no sujeito, ocorra primeiramente no campo do Outro, como forma de apelo. No autismo, no entanto, há impasses quanto à alienação aos significantes provenientes do Outro, sentidos como invasivos. Com isso, constatou-se que a introdução da musicalidade na clínica com esses sujeitos surge como possibilidade de deixar suas marcas, por se tratar de um elemento que permite mediação no âmbito da enunciação.

Palavras-chave: autismo, voz, lalíngua, psicanálise, música.

\section{About what Resonates and Echoes: Voice, Music and Lalingua in the}

\section{Autism Treatment}

\begin{abstract}
This article discusses the articulation between the psychoanalytic concepts of Lalíngua and speech, thought from the clinic with autistic subjects. Based on the clinical vignettes drawn from the literature and from the experience of working in Mental Health services, we seek to investigate in what ways these theoretical notions are presented primarily in the act of
\end{abstract}

ISSN 1808-4281 
listening and how these can indicate a direction of treatment in autism from the music. The musicality of the mother's voice, through a resonance that does not attach to the sense, transmits an invocation to the infans so that it comes as subject, producing marks to be read. Such an invocation, so that it may resonate in the subject, must first occur in the field of the Other, as a form of appeal. In autism, however, there are impasses regarding the alienation to the signifiers from the Other, sensed as invasive. With this, it was verified that the introduction of musicality in the clinic with these subjects appears as a possibility to leave their marks, because it is an element that allows a mediation in the ambit of the enunciation.

Keywords: autism, voice, lalíngua, psychoanalysis, music.

\title{
Sobre lo que Resona y Hace Eco: Voz, Música y Lalíngua en el Tratamiento
}

\author{
del Autismo
}

\section{RESUMEN}

Este artículo aborda la articulación entre los conceptos psicoanalíticos de lenguas y de voz, pensados a partir de la clínica con sujetos autistas. Con base en las viñetas clínicas retiradas de la literatura y de la experiencia de trabajo en servicios de Salud Mental, se busca investigar de qué formas esas nociones teóricas se presentan primordialmente en el acto de escucha y cómo éstas pueden indicar una dirección de tratamiento en el autismo a partir de la música. La musicalidad de la voz materna, por medio de una resonancia que no se prende al sentido, transmite una invocación al infans para que éste venga como sujeto, produciendo marcas a ser leídas. Tal invocación, para que pueda resonar en el sujeto, es necesario que ocurra primero en el campo del Otro, como forma de apelación. En el autismo, sin embargo, hay impases en cuanto a la alienación a los significantes provenientes del Otro, sentidos como invasivos. Con ello, se constató que la introducción de la musicalidad en la clínica con esos sujetos aparece como posibilidad de dejar sus marcas, por tratarse de un elemento que permite una mediación en el ámbito de la enunciación.

Palabras clave: autismo, voz, lalíngua, psicoanálisis, música.

Na musicalidade da voz materna há algo que não se prende ao sentido e que, por meio de sua ressonância, transmite uma invocação ao infans para que este advenha como sujeito (Catão \& Vivès, 2011). É através da mãe, ou de quem ocupa essa função para a criança, que se produz a impressão da marca do significante implicada na pulsão invocante e em lalíngua - neologismo utilizado por Lacan (1971-72/1997) para se referir ao modo como cada pessoa se apropria de sua língua materna. Estas últimas noções supracitadas são responsáveis pelos primeiros banhos linguísticos transmitidos, que têm a função de inscrever o infans no campo simbólico, tornando-o um corpo impregnado de linguagem (Catão, 2009). 
Assim, a criança escuta e é um ser falado antes mesmo que se constitua falante. No entanto, o ato de escutar não é algo natural e implica diversos fatores tais como as modalizações da voz do Outro (Catão, 2009). Nesse sentido, no que se refere aos ditos autistas, a "recusa" ao campo simbólico fez com que alguns estudiosos dessem ênfase ao estatuto da fala nesses sujeitos, não se interrogando, suficientemente, acerca de outro aspecto fundamental: “o que ouvem os autistas?”, discussão já indicada por Lacan (1975/1991, p.134) em sua Conferência em Genebra sobre o Sintoma: "Eles ouvem muitas coisas", uma vez que, "articulam muitas coisas e se trata de ver precisamente onde escutaram o que articulam".

Tal passagem nos remete, portanto, à relação do sujeito que escuta com o Outro, e as consequências na sua constituição. Perguntamo-nos: de que forma voz e la língua se articulam enquanto elementos presentes nessa transmissão primordial no ato de escuta? Como tais noções estão implicadas na clínica do autismo e de que modo podem ajudar-nos a refletir acerca da direção de tratamento, considerando a dimensão musical implicada?

A voz, enquanto objeto pulsional, implica a presença do Outro, o que na psicose, e mais especificamente no autismo, aparece como uma vivência massiva e não dialetizável. E isso ocorre de tal modo que é preciso anulá-la, apaziguá-la. Se, no que tange à paranoia, o psicótico carrega o objeto a no bolso (Lacan, 1967/1998), os autistas são o objeto e estão presos / petrificados no bolso do Outro, constituindo-se pela sua defesa contra a invasão de gozo (Monteiro, 2011). O que resta, então, é "a tentativa de tapar os ouvidos ao que não pode passar a voz, permanecendo então como barulho" (Catão, 2009, p.113).

Se, para esses sujeitos, o peso das palavras refere-se ao efeito de perda do gozo consequente da introdução do significante com seus equívocos e significações - a introdução da melodia de lalíngua aparece como possibilidade de deixar suas marcas a partir da qual alguma articulação e deslizamento possam surgir. É nesse sentido que a dimensão musical pode se fazer presente no tratamento, por permitir uma mediação na qual a palavra pode aparecer circunscrita quanto à enunciação, diminuindo o peso dos equívocos que lhe são próprios, possibilitando a inscrição de algo do significante a partir de lalíngua (Lacan, 197273/1985) e transformando o barulho e o ruído, em voz.

Assim, neste estudo - que recorre à vinhetas clínicas retiradas da literatura e da experiência de trabalho em serviços de Saúde Mental — apresentamos, inicialmente, algumas considerações teóricas acerca das noções psicanalíticas de voz e lalíngua, para, posteriormente, estabelecermos suas relações entre si e a clínica do autismo, sem deixar de considerar, no entanto, a função da musicalidade nesse contexto. Tal função é entendida como 
algo que ultrapassa o que é possível de ser significado pela palavra, além de estar relacionada ao chamamento contido na pulsão invocante.

\section{A Ressonância e o Eco do Dizer: Articulações entre Voz e Lalíngua}

O termo lalíngua, também traduzido por alíngua, surge de um lapso produzido por Lacan: quando quis se referir ao livro "Vocabulário de Psicanálise", disse "Vocabulário de Filosofia", o que implicava a troca em torno do nome de seus respectivos autores: Laplanche e Lalande. E, assim, com a proximidade fonética que sua língua permite, Lacan (197172/1997, p. 15) desliza de "Lalande", para "lalangue", unindo o artigo francês la e a palavra langue: "Enfim, isso vale o Lalande... Lalangue, como escrevo agora, não tenho quadronegro, bem, escrevam alíngua [lalangue] numa só palavra; é assim que escreverei doravante”. O autor se utiliza desse neologismo, formado por seu inconsciente, para se referir ao efeito da linguagem sobre o sujeito, antes que se tenha um sentido articulado. A linguagem que se transmite através da língua materna, atravessa cada sujeito de um modo particular a partir do que lhe foi falado e de como foi escutado. Assim, uma vez que lalíngua é considerada "um operador lacaniano fundamental para trabalhar a questão do que se transmite através da voz materna" (Lima \& Poli, p.72), torna-se oportuno investigar, primeiramente, de que forma se articulam a noção de voz e lalíngua e como estas se apresentam no ato de escuta.

Santos e Caldas (2012) afirmam que lalíngua tem relação com a voz, na medida em que esta última, enquanto objeto $a$, apresenta o desejo do Outro, apontando que ambas afetam o corpo com suas vibrações e musicalidade, possibilitando o surgimento do sujeito. Para Quinet (2010), o gozo que marca o corpo do sujeito é proveniente da música de lalíngua, que, uma vez "ouvida e lalada", leva o corpo a movimentar-se "no ritmo das pulsões".

A voz, apesar de não ter sido descrita por Freud como um objeto pulsional, foi reconhecida por ele como um elemento para pensar as primeiras experiências com o mundo externo (Vivès, 2009). A partir da releitura de Lacan (1962-1963/2005), foi possível acrescentar a voz enquanto objeto da pulsão invocante, destacando que esta não é vinculada à fonetização. Dizer isso permite pensar a fonetização do lado da fala, e por isso, separada da voz. Nesse sentido, fala e voz são elementos diferentes: a fala permite um suporte e é ligada ao sentido, enquanto a voz é acessível somente pelos restos da fala e o que chega além do sentido.

Ademais, a voz possui uma entonação e um timbre que funciona como um registro de um traço único do sujeito (Lacan, 1961-1962/2003), considerado como um aspecto simbólico 
da voz. No que se refere à pulsão invocante, esta diz do apelo, que é, consequentemente, direcionado a alguém: o Outro. Assim, é necessário que a voz seja endereçada para que alguém a tenha como enigma (Lacan, 1962-1963/2005), ou seja: para que o significante da voz possa ressoar no sujeito, é necessário que ele o faça primeiramente no campo do Outro.

Consideramos que essa dimensão da ressonância está intrinsecamente relacionada à noção de lalíngua, uma vez que, antes mesmo de Lacan ter forjado tal conceito na década de 1970, já é possível localizar - desde o início do seu ensino - uma preocupação com o Real da língua implicando a dimensão musical e ressonante. No texto Função e campo da fala e da linguagem em psicanálise (Lacan, 1953/1998), o autor dedica a parte final do relatório ao que chama de "ressonância da interpretação e da linguagem", relacionando a interpretação à resposta do analista. No artigo A Instância da letra no inconsciente ou a razão desde Freud, ele afirma (Lacan, 1957/1998, p. 506-507, destaque nossos): "Mas basta escutar a poesia, o que sem dúvida aconteceu com F. Saussure, para que nela se faça ouvir uma polifonia e para que todo discurso revele alinhar-se nas diversas pautas de uma partitura".

No seminário A Angústia (Lacan, 1962-1963/2005, p. 300), Lacan afirma que a importância da voz está relacionada não ao fato de ressoar em um espaço qualquer, mas por ressoar no vazio do campo do Outro, algo que pode ser produzido a partir do momento em que a voz é incorporada como alteridade do que é dito. A concepção de ressonância é retomada e destacada por Lacan mais de uma década depois de ter cunhado a noção de pulsão de invocante, quando o mesmo aponta que: “As pulsões são, no corpo, o eco do fato de que há um dizer. Esse dizer, para que ressoe, (...), é preciso que o corpo lhe seja sensível. É um fato que ele o é." (Lacan, 1975-1976/2007, p. 18-19). Aqui é importante destacar que eco e ressonância, apesar de serem fenômenos acústicos, não são sinônimos. Há ressonância quando um sistema físico qualquer recebe excitações de frequências de vibração iguais às suas e assim uma ampliação destas (Nussenzveig, 2002). Se não houver essa "sintonia", não há ressonância. Já o eco é a repetição de um som pela sua reflexão numa superfície ou objeto, ou seja, um corpo (Wilson, 2006). Podemos, então, entender, a partir das palavras de Lacan, que é preciso que o "dizer" tenha relação com o sujeito - tenha a mesma "frequência" - para que nele ressoe e, assim, se obtenha seu efeito / sua resposta, que é o eco no corpo, a pulsão. Tal afirmação é coerente com outra passagem contemporânea, referida aos autistas: "É muito precisamente o que faz com que não os escutemos. O fato de que eles não nos escutam. Mas finalmente sem dúvida há algo para lhes dizer" (Lacan, 1975/1991, p. 134). Ora, se a ressonância da palavra é algo constitutivo, como podemos conceber sujeitos que parecem não escutar e se recusam a responder a tal ressonância, abafando seu eco? 
Quanto a isso, é importante lembrar que a incorporação primordial da voz só ocorre com o consentimento da criança (Catão \& Vivès, 2011, p. 85), o que confirma que o sujeito não é totalmente passivo diante do Outro. Há de se considerar, portanto, como o sujeito recebe o que vem do Outro - o modo como escuta - e se isso lhe ressoa e faz enigma. Entendemos, ainda, que, se há recusa desse eco, ela é, em si, a resposta mesma à ressonância do dizer. Portanto, para nós, é necessário e ético dizer que não se trata de um corpo deficiente insensível às palavras. Desse modo, a subjetivação ou não de lalíngua e da voz por parte do sujeito é determinante quanto à sua entrada no mundo dos significantes e toca na escolha que Lacan chamou de "insondável decisão do ser" (Lacan, 1946/1998), algo que consideramos totalmente pertinente no que se refere à discussão em torno da clínica do autismo, que será melhor explanada adiante.

\section{Voz e Lalíngua na Clínica do Autismo}

Na perspectiva de articulação entre lalíngua e a pulsão invocante, concordamos com Catão e Vivès (2011), quando descrevem os tempos lógicos de estruturação psíquica momento mítico de um tempo que antecede a existência do sujeito do inconsciente. Os autores propõem que é preciso pensar a dinâmica constitucional a partir das duas operações psíquicas já formuladas por Freud (1925/1979) e descritas por Lacan (1964/1985), chamadas de alienação e separação, como tempos sucessivos de afirmação (Bejahung) e negação / expulsão (Ausstossung). A alienação primordial ao campo da linguagem advém da afirmação, ou seja, do "sim" concedido pelo infans à voz do Outro (Didier-weill, 1997), aceitando incorporá-la.

O sujeito autista nos dá testemunhos de sua escolha ao não se deixar alienar completamente pelos significantes do Outro (Maleval, 2009), a forma como ele se relaciona com a linguagem / campo simbólico é a de se recusar ao ato de enunciação (Catão \& Vivès, 2011), parecendo não subjetivar os restos de lalíngua (Bastos \& Freire, 2006). Diante dessa recusa, temos: de um lado, o sujeito que não cede ao gozo vocal para quem a voz é excessiva (Maleval, 2009); e, de outro lado, vemos um sujeito "aprisionado" pelos detritos sonoros transmitidos por lalíngua (Bastos \& Freire, 2006). A divisão subjetiva, portanto, consiste justamente no apagamento da função do sujeito pela via da petrificação significante e a não abertura à dialetização pela perda do objeto vocal.

Consideremos um episódio de nossa experiência numa ação de extensão universitária voltada a crianças em grave sofrimento psíquico. Em uma atividade de grupo, havia uma 
garota de 8 anos, diagnosticada com autismo, a qual chamaremos Lara, atendida pelo serviço há alguns anos. Um dia, Lara sai da sala e passa a gritar perto da recepção de forma ecolálica a seguinte frase: “Alô, mãe! Alô, mãe!". Diante do incômodo gerado, alguns integrantes do grupo tentavam contê-la, insistindo que a garota voltasse à sala. No entanto, Lara continuava gritando cada vez mais alto. Uma das alunas extensionistas ${ }^{1}$ chega perto de Lara, coloca a mão no seu próprio ouvido imitando um telefone e diz "Alô, é a mãe da Lara? Você pode pedir para que ela entre na sala?". A partir dessa intervenção, a garota diz, "Sim, mamãe." e volta tranquilamente à sala. Nessa situação, podemos perceber que a extensionista dirigiu-se à Lara indiretamente, reduzindo o impacto do "excesso de voz" destacado por Maleval (2009).

Tal excesso é evidenciado por Monteiro (2011, p. 52-53) quando a autora aponta que, na clínica do autismo, podemos presenciar manifestações nas quais há uma desorganização corporal que se dá a partir do gozo excessivo que afeta esses sujeitos. Esse excesso proveniente de uma desordem pulsional - é efeito da não operação de extração do objeto $a$ que teria a função de regular tal gozo (Monteiro, 2011).

Tal operação já era indicada por Freud em 1920, quando apresenta o jogo do Fort-da realizado por seu neto. O Fort-da representa a operação de perda do objeto e a resposta da criança ao excesso traumático desta por meio da repetição, o que nos conduz a pensar acerca do momento originário de simbolização e a articulação entre a oposição dos significantes primordiais, S1 (Fort) e S2 (Da) ilustrado por Freud, e só possível de ser pensado com esses fonemas em sua língua. No autismo, porém, vemos uma não articulação entre S1 e S2. Como consequência, o que se apresenta é um "enxame ${ }^{2}$ de significantes não articulados" (Monteiro, 2011, p. 52-53). Ribeiro (2005, p. 169), fala que o trabalho de repetição no autismo trata-se da "tentativa de inscrever um S2, de estabelecer um "mais e um menos", um Fort-da", absolutamente coerente com a afirmação de Lacan quanto à tentativa vã e reiterada do esquizofrênico de dar o passo que simboliza o vazio delineado na hiância produzida pela alternância do par de opostos, “... Já que, para ele, todo o simbólico é Real”. (Lacan, 1954/1998, p. 394).

Lembramos também de Bete, uma garota dita autista de cinco anos que foi atendida em um dispositivo universitário de clínica-escola. Logo que chegou, apresentava grande dificuldade de interação e quase não verbalizava. Em alguns momentos apresentava ecolalias, consideradas pelos seus pais e pessoas mais próximas como atos sem sentido que deveriam ser retirados da criança através do tratamento. Nos primeiros atendimentos, Bete demonstrava ter a voz do Outro como insuportável. Ao escutar qualquer frase advinda da analista, a garota tapava os ouvidos e repetia a palavra "não", batendo a cabeça em uma porta de vidro. Esse 
comportamento era repetido sem nenhuma pausa, até que a analista passa a dizer a palavra "sim" de forma melódica nos intervalos das falas da garota, batendo de forma rítmica com uma baqueta na mesma porta. A partir de então, Bete olha para a analista, tira as mãos do ouvido e pergunta "sim?", ao que a analista responde "não", melodiosamente, construindo em seguida uma brincadeira entre as duas. Nessa brincadeira, cada uma respondia com a palavra contrária (sim-não) em alternância. Nesse jogo, Bete se divertia e mostrava euforia, conseguindo substituir o comportamento de tapar os ouvidos, que testemunhava a dificuldade da garota de escutar a voz do Outro.

A fala de Bete, interpretada como uma pergunta constituiu nesse instante um esboço de demanda. O que se seguiu em uma "música" construída pela analista e por Bete, atravessada pela percussão da baqueta e por suas vozes. Nos atendimentos posteriores, Bete sempre retornava a brincadeira do "sim-não" e brincava com as sonoridades em sessão, enxertando ritmos, intervalos e oposições. O movimento repetitivo e ecolálico transformou-se numa enunciação musical. Estes são exemplos de tentativas indiretas de se dirigir a essas crianças subtraindo o excesso de gozo que lhes afeta pela via de um objeto artificial para o qual emprestamos / desviamos a enunciação. Aqui vemos a simulação de um telefone e o uso de uma baqueta. A encenação do telefone e o instrumento percussivo musical juntamente com a melodia, constituem o que Vivès (2009) descreve como "doma-voz" — análogo ao "domaolhar" de Lacan (1964/1985) —, servindo para aplacar o gozo do Outro em sua injunção superegóica e invasiva. Logo, observamos a proteção do autista em relação ao objeto voz, na sua relação direta com o sujeito. A música se apresenta, então, como manifestação essencialmente humana, por permitir domar e circunscrever a angústia e o gozo relativos à presença do objeto pulsional que ameaça o sujeito. Assim, passaremos a discutir de que forma a dimensão musical implicada na voz e em lalíngua pode se fazer presente na direção de tratamento no autismo.

\section{Do Ruído Inarticulado à Voz: Uma Direção de Tratamento Possível a partir da Música}

De acordo com Maleval (2009), a criança autista utiliza o mutismo ou artifícios próprios para evitar, tanto a sua própria voz quanto a do Outro. Donna Williams, escritora autista que relata sua própria história, nos diz: "Não eram as palavras das pessoas que me traziam problemas, mas as suas expectativas quanto as minhas respostas". Afirmação coerente com Lacan (1975/1991, p. 134-135) quando se refere aos autistas: "Eles não conseguem escutar o que o Sr. tem para dizer-lhes enquanto o Sr. se ocupa deles”. O que significa que 
não é a palavra em sua materialidade que é problemático, mas o desejo que carrega, o que ela simbolicamente representa de demanda do Outro.

Ainda nessa mesma passagem de sua Conferência de Genebra sobre o Sintoma, Lacan (1975/1991, p. 135) aponta que o autista "talvez só escute o barulho, isto é, que tudo a seu redor murmura”. Catão (2009, p. 179) afirma que "tapar os ouvidos é, no autismo, um expediente insuficiente para fazer calar o real da voz, que insiste em se presentificar como ruído (...) O barulho o invade e não traz nenhuma informação a seu respeito". Podemos sugerir, portanto, que o movimento de transformação do ruído em música pode ser uma forma análoga à afirmação de Lacan de "extrair de lalíngua o que é do significante" (Lacan, 197273/1985). Tratar-se-ia, enfim, de uma tentativa de simbolização e estabelecimento da diferença entre significantes desarticulados — uma vez que a música é definida enquanto a "extração do som ordenado e periódico do meio turbulento dos ruídos" (Wisnik, 1999, p. 27).

Sabemos que os instrumentos e as cordas vocais emitem sons que afetam o corpo, sem necessariamente estarem ligados à ordem da compreensão e do significado. É isso que ilustra a relação das noções de lalíngua e de voz com a dimensão musical, já discutida por vários autores do campo da psicanálise (Quinet, 2012; Lima \& Poli, 2012; Schwarz \& Moschen, 2012; Vivès, 2009; Didier-Weill, 1999). No que concerne à forma com que a relação dessas noções se expressa na clínica do autismo, Didier-Weill (1999, p. 152), aponta que muitos analistas que atendem crianças autistas observam que as mães destas se apresentam, frequentemente, com vozes "despojadas de seu sopro vocal”. O autor justifica sua afirmação dizendo que "muito antes da transmissão do significado, é por intermédio daquilo que o som musical tem de assemântico que a passagem do simbólico mais originário pode se transmitir de maneira humanizadora”. Outrossim, Didier-Weill (1999) deixa-nos uma inquietação, formulando que os psicanalistas são requisitados a compreender melhor do que se trata "a eficácia do som musical sobre a foraclusão", algo que testemunhamos continuamente em nossa experiência.

Recuperamos, então, um caso também oriundo do trabalho na clínica-escola supracitada, que se refere a um garoto dito autista de 6 anos que chegou ao tratamento no serviço. O menino, que chamaremos de Elton, não falava, apenas apresentava gritos e murmúrios desarticulados. O mesmo adorava sentir as vibrações dos sons e mostrava-se sempre bastante animado quando escutava música. Elton apresentava-se indiferente em relação às pessoas ao seu redor, interagindo com dificuldade. Em um dos atendimentos, a extensionista que o acompanhava produz uma melodia com o nome do garoto, nome este que era formado inicialmente por uma vogal forte e terminava com um fonema consonantal que se 
assemelhava ao som de um tambor. Assim, os dois fonemas eram repetidos melodiosamente em uma improvisação musical. Utilizando os instrumentos musicais que produziam tais sons, a extensionista passa a cantar e repetir para Elton, que escutava e pulava euforicamente, até que, pegando no rosto da extensionista, o garoto emite o seu próprio nome. Primeiramente cantando e logo depois falando sem melodia. Esta foi a primeira vez em que se ouviu uma palavra por parte do garoto.

Nessa perspectiva, outra passagem bastante ilustrativa é fornecida por Donna Williams (2012) quando relata sua vivência na visita a uma escola voltada para crianças autistas. Ela fala sobre o seu contato com uma menina chamada Anne, que tinha surdez e cegueira. Segundo a autora, Anne tinha frequentes crises nervosas e era tratada de forma bastante agressiva pelas cuidadoras do ambiente que não entendiam sua condição. Williams descreve Anne como uma criança de "olhos entorpecidos e olhar morto". Conta a autora como conseguiu lidar com a situação:

Peguei sua mão e a fiz dar tapinhas em seu próprio braço como eu o fazia, mantendo a cadência no mesmo ritmo hipnótico. Ouvi então uma doce cadência, quase inaudível e que não vinha de mim. Era Anne que sussurrava a melodia com a garganta. Omiti algumas notas e, como eu o esperava, ela continuou como se o refrão houvesse sempre sido o dela. Eu saltava progressivamente cada vez mais as notas, até o momento em que ela não se contenta mais em marcar o ritmo em sua garganta, mas começa realmente a cantarolar batendo a cadência no braço (...). Eu saía várias vezes, unicamente para poder, em seguida, repetir o exercício. $\mathbf{O}$ importante é que durante a minha ausência, ela foi capaz de cantarolar marcando o ritmo, por si mesma, entre cada manifestação de medo (Williams, 2012, p.311, grifo nosso).

Abreu (2008) sugere, a partir de sua experiência, que, por meio da música na relação transferencial com esses sujeitos, é possível haver a queda do objeto a e traz a hipótese de que, na música, esse objeto entra em operação a partir da queda daquilo que o compõe no momento em que a música se transforma em ato no encontro com a falta. Algo que testemunhamos nos exemplos acima. Assim, Williams (2012) se ausentava, delimitando um vazio e uma falta, para que a criança pudesse apresentar-se, e marcar, "por si mesma", um ritmo.

Catão (2009) levanta a hipótese de que, no tratamento com estas crianças, uma vez que a suposição de sujeito está do lado do analista a3, este último pode utilizar um texto 
imaginário para transmitir o simbólico, buscando propiciar a transformação dos signos em que a criança está presa / congelada para a função de significante, fazendo surgir uma dimensão de alternância. Ou como nos diz Vorcaro (1999, p. 69), se trata de auxiliar a criança a "produzir o Real ao invés de sofrê-lo". Esse real pode ser construído de diversas formas, seja com brincadeiras ou até mesmo através do aspecto musical, que aponta para o que não se liga ao sentido.

Nessa lógica, Vivès (2016) diz que os sujeitos autistas resistem ao peso que constitui a voz. Para ilustrar sua afirmação, o autor relata uma experiência desenvolvida com uma criança autista, a partir da qual foi utilizado um robô para interagir com a mesma. Esta criança não respondia a voz humana, apenas à fala do robô, mesmo que a fala deste fosse emitida por meio de um computador no qual as pessoas transmitiam sua mensagem digitando e transferindo para a voz maquínica. A partir desta experiência, o autor questiona-se acerca das propriedades específicas que estão presentes na fala daquele robô que faz com que a criança a responda, não se defendendo diante dela. Diante disso, o autor chega à conclusão de que na voz maquínica trata-se de uma voz sem sujeito, e, portanto, esvaziada do "peso real do sujeito”, o qual Lacan (1958-1959/2002, p. 411) se refere. Segundo Vivès (2016) esta voz está destituída do que ela tem de mais singular: o timbre, e, por isso, é possível ser investida pelo autista. Diz o autor: "As crianças autistas, quando assumem o risco de falar, assumem um acordo: a voz vai sem timbre, como se fosse uma voz maquínica. Uma voz que não é habitada". (Vivès, 2016).

Pra prosseguir nessa reflexão é importante retomar, antes de tudo, os padrões musicais do som, que seriam: a altura (que pode ser mensurada a partir de um som agudo ou grave), a frequência (que é medida em hertz), a duração (que é dada em segundos) e, por último, a potência (que é medida em decibéis). O timbre, no entanto, é o único elemento sonoro de difícil mensuração, por não ter uma unidade de medida específica, podemos apenas tentar descrevê-lo. Além de não estar submetido a uma escala gradual, o timbre está vinculado aos "traços qualitativos" do som, devido a sua particularidade e singularidade material (Wisnik, 1999, p. 16). Dito de outra forma, "O timbre é a dimensão real da voz, é o que escapa a apreensão pelo simbólico. Timbre é o peso real do sujeito no discurso. É o que nos permite conhecer uma voz" (Vivès, 2016).

O timbre é a marca da presença do corpo, na voz de um instrumento (Wisnik, 1999), ele implica, sobretudo, a introdução dos ruídos deste corpo na onda sonora por ele emitido. A rigor, o timbre de um corpo sonoro é a distorção que é imiscuída no som, marcando sua singularidade. Assim, entendemos a perspectiva de Vivès, de considerar que a presença do 
peso Real do sujeito no discurso se transmite pelo timbre e pela modulação de sua voz através do "ato de um dizer", uma enunciação. E isso implica, por sua vez, não apenas o timbre de uma voz, mas sua prosódia, sua musicalidade e seu saber-fazer com o objeto, no qual o timbre é mais um de seus componentes. Neste sentido, o timbre não é simplesmente a marca da presença do sujeito, mas a marca de seu gozo singular e a intromissão do real de seu corpo. Podemos concluir que a música de lalíngua, carregada pela voz que se perde com a assunção ao significante, torna-se um elemento capaz de mediação que permite ao sujeito incluir o Outro a partir de seu tratamento ${ }^{4}$.

\section{Considerações Finais}

Conforme apresentamos, entende-se que lalíngua é transmitida pela voz e seduz pela ausência de significado e por sua musicalidade. Eis o ponto de articulação principal dessas noções teóricas e que tentamos responder nesse trabalho. Ademais, o conceito de lalíngua, remetido à lalação das crianças, anterior à articulação significante (Lacan, 1972-1973/1985), confirma que a ênfase da transmissão primordial está não no significando do que o Outro diz, mas na forma como é dito, na sua modulação e ressonância. Estas têm efeito no corpo, que, segundo Lacan (1962-63/2005), tem uma marca que permite localizá-lo em uma cadeia de significantes. Além disso, os detritos sonoros advindos do Outro podem se depositar no corpo por meio de afetos (Lacan, 1972-1973/1985) e, assim, esboçar ou articular algo a partir do encontro com as palavras (Lacan, 1975/1991). Uma vez que não conseguimos localizar a função do sujeito, dificilmente se tem acesso ao que do significante deixou esses detritos, essas marcas.

É incontestável e paradoxal, uma vez que usamos o termo autismo - que esses sujeitos não são imunes às ressonâncias da palavra. Sua própria "surdez seletiva" em relação à voz (Didier-Weill, 1999), já é um indício de que são afetados pelo campo simbólico e que algo impacta o seu corpo. Nessa perspectiva, passamos a nos interrogar de que forma a dimensão musical - e ressonante - presente em lalíngua, poderia ajudar na direção do tratamento dos ditos autistas. Constatamos - baseados na vivência clínica e com o nosso percurso teórico - que o trabalho se relaciona ao que, no sujeito, faz ressonância e ecoa nas diversas formas de resposta que ele dá ao que escuta. Sustentamos essa compreensão em concordância com Lacan (1975/1991) quando enfatiza que é difícil imaginar sujeitos que não escutem, uma vez que a ressonância da palavra é algo constitucional, mas que devemos buscar onde escutaram o que articulam. Em resumo, percebemos a importância do recurso à 
música como uma possibilidade tática no tratamento, tendo em vista que ela abarca a dimensão enunciativa por uma via indireta, permitindo a proteção necessária contra a angústia relativa ao objeto pulsional da voz. Assim, a música empresta à voz uma vestimenta do som, possibilitando que a palavra seja dita e, assim, o sujeito possa encontrar mais leveza em si, no Outro e no mundo.

\section{Referências}

Abreu, F.M. (2008). O lugar ético dos sons musicais quando significantes na clínica e na política de saúde mental infanto-juvenil (Dissertação de Mestrado). Programa de pósgraduação em Psicanálise, Universidade do Estado do Rio de Janeiro, Rio de Janeiro, RJ, Brasil. Recuperado de http://www.bdtd.uerj.br/tde_busca/arquivo.php?codArquivo=1259

Bastos, A. (2014). A voz na experiência psicanalítica. Ágora, 27(1), 59-70. doi:10.1590/S1516-14982014000100004

Bastos, A., \& Freire, A. B. (2006). Sobre o conceito de alíngua: Elementos para a psicanálise aplicada ao autismo e às psicoses. In A. Bastos (Org), Psicanalisar hoje (pp. 107-122). Rio de Janeiro: Contra Capa.

Catão, I. (2009). O bebê nasce pela boca: Voz, sujeito e clínica do autismo. São Paulo: Instituto Langage.

Catão, I, \& Vivès, J-M. (2011). Sobre a escolha do sujeito autista: Voz e autismo. Estudos de $\begin{array}{llll}\text { Psicanálise, } & \text { (36), } & \text { 83-92. } & \text { Recuperado }\end{array}$ http://pepsic.bvsalud.org/scielo.php?script=sci_arttext\&pid=S0100$34372011000300007 \& \operatorname{lng}=\mathrm{pt} \& \operatorname{tlng}=\mathrm{pt}$

Didier-Weill, A. (1997). Os Três Tempos da Lei: O mandamento liderante, a injunção do supereu e a invocação musical. Rio de Janeiro: Zahar.

Didier-Weill, A. (1999). Invocações: Dionísio, Moisés, São Paulo e Freud. Rio de Janeiro: Companhia de Freud.

Freud, S. (1977). Pulsiones e destinos de pulsión. In S. Freud, Edição Obras completas (Vol. 14). Buenos Aires: Amorrortu. (Obra original publicada em 1915)

Freud, S. (1979). La negación. In S. Freud, Edição Obras completas (Vol. 19). Buenos Aires: Amorrortu. (Obra original publicada em 1925)

Freud, S. (1985). Tres Ensayos de teoría sexual. In S. Freud, Edição Obras completas (Vol. 7). Buenos Aires: Amorrortu. (Obra original publicada em 1905) 
Freud, S. (1985). Más allá del principio del placer. In S. Freud, Edição Obras completas (Vol. 18). Buenos Aires: Amorrortu. (Obra original publicada em 1920)

Grandin, T. (1999). Uma menina estranha (S. Flanksman, Trad.). São Paulo: Companhia das Letras.

Klein, M. (1996). A importância da formação de símbolos no desenvolvimento do ego. In A. Cardoso (Trad.), Amor, culpa e reparação e outros trabalhos. (pp. 249-264). Rio de Janeiro: Imago. (Texto original publicado em 1930)

Lacan, J. (1979). O seminário. Livro 1: Os escritos técnicos de Freud. Rio de Janeiro: Jorge Zahar. (Obra original publicada em 1953-1954)

Lacan, J. (1985). O seminário, livro 3: As Psicoses. Rio de Janeiro: Jorge Zahar. (Obra original publicada em 1955-1956)

Lacan, J. (1985). O Seminário, Livro 11: Os quatro conceitos fundamentais da psicanálise. Rio de Janeiro: Jorge Zahar. (Obra original publicada em 1964)

Lacan, J. (1985). O seminário. Livro 20: Mais, ainda. Rio de Janeiro: Jorge Zahar. (Obra original publicada em 1972-1973)

Lacan, J. (1991). Conferência em Genebra sobre o sintoma. In J. Lacan, Intervenciones y textos (pp. 6-16). Buenos Aires: Ediciones Mnantial. (Obra original publicada em 1975)

Lacan, J. (1992). O seminário, livro 17: O avesso da Psicanálise. Rio de Janeiro: Zahar. (Obra original publicada em 1969-1970)

Lacan, J. (1997). O Saber do Psicanalista: Seminário. Recife: Centro de Estudos Freudianos de Recife. (Obra original publicada em 1971-1972)

Lacan, J. (1998). Formulações sobre a causalidade psíquica. In J. Lacan, Escritos (pp. 152194). Rio de Janeiro: Jorge Zahar. (Obra original publicada em 1946)

Lacan, J. (1998). Função e campo da fala e da linguagem em psicanálise. In J. Lacan, Escritos (pp. 238-324). Rio de Janeiro: Jorge Zahar. (Obra original publicada em 1953)

Lacan, J. (1998). Resposta ao comentário de Jean Hypollite sobre a "Verneinung" de Freud. In J. Lacan, Escritos (pp. 383-401). Rio de Janeiro: Jorge Zahar. (Obra original publicada em 1954)

Lacan, J. (1998). A instância da letra no inconsciente ou a razão desde Freud. In J. Lacan, Escritos (pp. 496-533). Rio de Janeiro: Jorge Zahar Editor. (Obra original publicada em 1957)

Lacan, J. (1998). Alocução sobre as psicoses da criança. In J. Lacan, Escritos (pp. 359-368), Rio de Janeiro: Jorge Zahar. (Obra original publicada em 1967) 
Beatriz Alves Viana, Kemylle Mesquita Brito, Luis Achilles Rodrigues Furtado

Lacan, J. (2002). O desejo e sua interpretação: Seminário 1958-1959. Porto Alegre: Associação Psicanalítica de Porto Alegre. (Obra original publicada em 1958-1959)

Lacan, J. (2003). A identificação. Recife: Centro de Estudos Freudianos de Recife. (Obra original publicada em 1961-1962)

Lacan, J. (2005). O seminário, livro 10: A angústia. Rio de Janeiro: Jorge Zahar. (Obra original publicada em 1962-1963)

Lacan, J. (2007). O Seminário, Livro 23: O Sinthoma. Rio de Janeiro: Jorge Zahar. (Obra original publicada em 1975-1976)

Lima, C. M., \& Poli, M. C. (2012). Música e um pouco de silêncio: Da voz ao sujeito. Ágora, 15(spe), 371-387. doi:10.1590/S1516-14982012000300002

Maleval, J. (2009). El altista y su voz. Madrid: Editorial Gredos.

Monteiro, K. A. C. (2011). O Tratamento do Gozo no Autismo: Clínica Psicanalítica e Objetos Autísticos (Dissertação de Mestrado). Programa de pós-graduação em Psicanálise, Universidade Federal do Rio de Janeiro, Rio de Janeiro, RJ, Brasil.

Nussenzveig, H. M. (2002). Curso de física básica. São Paulo: Edgard Blucher.

Quinet, A. (2010). CORPOEMA: O homem, ser-para-arte, e seu corpo. Stylus: Revista de Psicanálise, 21(1), 19-26. Recuperado de https://issuu.com/epfclbrasil/docs/stylus_21

Quinet, A. (2012). Psicanálise e Música: Reflexões sobre o inconsciente equívoco. Música e Linguagem, 1(1). Recuperado de http://www.periodicos.ufes.br/musicaelinguagem/article/view/3597/3298

Ribeiro, J. M. (2005). A criança autista em trabalho. Rio de Janeiro: 7 Letras.

Santos, V., Caldas, H. (2012). Há voz na surdez? (La)língua dê sinais. Anais do V Congresso Internacional e XI Congresso Brasileiro de Psicopatologia Fundamental: Dietética, corpo e pathos, 2012 Fortaleza, NEPECC. Recuperado de http://www.psicopatologiafundamental.org.br/uploads/files/v_congresso/mr_9__viviane_do_espirito_santo_dos_santos_e_heloisa_caldas.pdf

Schwarz, C., \& Moschen, S. (2012). A pulsão invocante e o abismo das origens: Notas sobre a música e o silêncio. Cadernos de psicanálise, 34(27), 153-159. Recuperado de http://pepsic.bvsalud.org/scielo.php?script=sci_arttext\&pid=S141362952012000200009\&lng=pt\&tlng=pt.

Soler, C. (2007). O inconsciente a céu aberto da psicose. Rio de Janeiro: Jorge Zahar.

Soler, C. (2009). Lacan, l'inconscient reinventé. Paris: PUF. 
Vivès, J-M. (2009). Para introduzir a questão da pulsão invocante. Revista Latinoamericana de Psicopatologia Fundamental, 12(2), 329-341. doi:10.1590/S141547142009000200007

Vivès, J-M. (2016). Autismo e voz maquínica. Jornada Outrarte IEL Autismo: A voz e a clínica, Unicamp, Campinas, SP, Brasil, 1.

Vorcaro, A. M. R. (1999). Transferência e interpretação na clínica com crianças autistas e psicóticas. Estilos da Clinica, 4(7), 52-72. Recuperado de http://pepsic.bvsalud.org/scielo.php?script=sci_arttext\&pid=S1415$71281999000200006 \& \operatorname{lng}=p t \& t \operatorname{lng}=p t$

Williams, D. (2012). Meu mundo misterioso: Testemunho excepcional de uma jovem autista. Brasília: Thesaurus.

Wilson, C. (2006). As Faces da Física. São Paulo: Moderna.

Wisnik, J. M. (1999). O Som e o Sentido: Uma outra história das músicas. São Paulo: Companhia das Letras.

Zenoni, A. (1991). “Traitement” de l'autre. Préliminaire, Antenne, 110(3), 101-113.

\section{Endereço para correspondência}

\section{Beatriz Alves Viana}

Avenida Pasteur, 250, Urca, Rio de Janeiro - RJ, Brasil. CEP 21941-901

Endereço eletrônico: beatrizalvesv@ gmail.com

\section{Kemylle Mesquita Brito}

Avenida Lúcia Sabóia, 517, Centro, Sobral - CE, Brasil. CEP 62010-830

Endereço eletrônico: kemyllemb@gmail.com

\section{Luis Achilles Rodrigues Furtado}

Avenida Lúcia Sabóia, 517, Centro, Sobral - CE, Brasil. CEP 62010-830

Endereço eletrônico: luis.achilles@ gmail.com

Recebido em: 07/05/2019

Aceito em: 26/03/2020

\footnotetext{
Notas

* Psicóloga pela UFC. Mestre em teoria Psicanalítica pela UFJR. Especialista em Saúde Mental e professora do curso de psicologia do Centro Universitário Uninta.

** Psicóloga pela Universidade Federal do Ceará.

*** Professor do curso de Psicologia da Universidade Federal do Ceará.
} 
${ }^{1}$ Nome utilizado para referir-se aos alunos que fazem parte do Projeto de Extensão da Universidade na qual fazemos parte, que se trata de uma ação que acontece em serviços de Saúde Mental e é destinada a sujeitos em grave sofrimento psíquico e seus familiares.

${ }^{2}$ Termo que refere a significantes desarticulados, inúmeros S1, em francês "esse um" é homófono a "essaim" (Lacan, 1972-1973/1985).

${ }^{3}$ Entendemos, com Lacan (1969-1970/1992, p. 35), que, suposição de saber no sujeito está inicialmente do lado do analista em qualquer prática orientada pela psicanálise. E foi essa inversão que Freud promoveu no ato de fundação da psicanálise quando se calou e fez operar a associação livre com os pacientes neuróticos.

4 “Tratamento do Outro": Expressão utilizada para referir-se ao trabalho do sujeito autista de regular o excesso de gozo que o Outro representa (Zenoni, 1991).

Financiamento: CAPES e FUNCAP.

Este artigo de revista Estudos e Pesquisas em Psicologia é licenciado sob uma Licença Creative Commons Atribuição-Não Comercial 3.0 Não Adaptada. 